\title{
Gastrointestinal comorbidities in patients with psoriasis in the Czech Republic: The results of 189 patients with psoriasis and 378 controls
}

\author{
Katerina Juzlova ${ }^{\mathrm{a}, \mathrm{b}}$, Jana Votrubova ${ }^{\mathrm{a}, \mathrm{b}}$, Martina Dzambova ${ }^{\mathrm{a}, \mathrm{b}}$, Dana Gopfertova ${ }^{\mathrm{b}}$, Jana Hercogova ${ }^{\mathrm{a}}$, Zdeněk Smerhovsky ${ }^{\mathrm{b}}$
}

\begin{abstract}
Aims. The aim of the study was to investigate gastrointestinal comorbidities, identify risk factors and detect the early stages of autoimmune gastrointestinal diseases, such as Crohn's disease, ulcerative colitis and coeliac disease in patients with psoriasis.

Methods. This was a hospital-based case-control study. Patients with chronic plaque psoriasis were included as cases. The control group consisted of patients with other skin diseases and who complied with the same selection criteria as cases. Two controls were selected per one case. We analysed the following antibodies (ASCA, AEP, p-ANCA, AGC, EMA, ARA, tTG, AGA) and non-specific signs of gastrointestinal diseases.

Results. There were significant differences between cases and controls in several parameters. Leucocyte count, CRP, total protein, transglutaminase IgA antibodies and p-ANCA were statistically significant between groups $(P<0.05)$. In the binary logistic model, leucocyte count and p-ANCA (for all parameters included in the logistic model $P \leq 0.001$ ) were associated with psoriasis.

Conclusion. Patients with psoriasis should be regularly screened for coeliac and inflammatory bowel disease. Early diagnosis of gastrointestinal diseases and risk factors may prevent complications and greatly improve the patient's quality of life.
\end{abstract}

Key words: psoriasis, coeliac disease, inflammatory bowel diseases

Received: April 24, 2015; Accepted: September 11, 2015; Available online: October, 21, 2015

http://dx.doi.org/10.5507/bp.2015.048

${ }^{a}$ Department of Dermatovenereology, $2^{\text {nd }}$ Faculty of Medicine, Charles University in Prague, Czech Republic ${ }^{b}$ Department of Epidemiology, $2^{\text {nd }}$ Faculty of Medicine, Charles University in Prague, Czech Republic Corresponding author: Katerina Juzlova, e-mail: katerina.juzlova@gmail.com

\section{INTRODUCTION}

Psoriasis, coeliac disease and inflammatory bowel disease (IBD) are autoimmune diseases whose etiopathogenesis involves individual genetic predisposition as well as environmental factors.

Coeliac disease is characterized by permanent gluten intolerance. It manifests itself in genetically susceptible individuals (association with HLA-DQ2, HLA-DQ8) following a variable period after consuming cereals containing gluten. After the presentation to HLA-DQ2 and HLA-DQ8 positive cells, gliadin peptides induce an inappropriate T-cell mediated immune response in the intestinal mucosa. This simultaneously leads to the production of highly specific autoantibodies (anti - transglutaminase antibodies). The consequence of the reaction to gluten is damaged mucosa of the small intestine (mostly involving duodenum and jejunum) with varying degrees of atrophy and inflammatory changes ${ }^{1}$. The results of some recent studies show an increased occurrence of psoriasis in patients with coeliac disease ${ }^{1,2}$. The association between coeliac disease and psoriasis is strongly suggested as a gluten-free diet leads to a clear improvement and disappearance of psoriatic skin lesions in some patients ${ }^{3,4}$.

According to Aggarwal et al., the screening of coeliac disease in asymptomatic individuals suffering from an autoimmune disease is recommended ${ }^{5}$. Sensitive serological testing for autoantibodies, such as EMA (anti endomysium antibodies IgA, IgG), ARA (anti - reticulin antibodies), tTG (anti - transglutaminase antibodies IgA, $\mathrm{IgG}$ ) and AGA (anti - gliadin antibodies IgA, $\mathrm{IgG}$ ) were carried in our study. These tests are used in the screening and diagnosis of coeliac disease and in monitoring disease activity ${ }^{1,6,7}$.

Inflammatory bowel diseases are chronic relapsing disorders of the gastrointestinal tract of unknown etiol$\mathrm{ogy}^{8}$. In IBD patients, autoantibodies to various antigens have been identified, but only p-ANCA and ASCA have sufficient sensitivity and specificity to be effective for use in clinical practice 9 .

It has been suggested that the occurrence of inflammatory bowel diseases in genetically predisposed individuals is due to the dysregulation of the inflammatory response to intestinal microbes. The genes IL12B and IL23R are involved in the regulation of this pathway in Crohn's disease and ulcerative colitis. A study of the Swedish and Finnish population confirms the association between psoriasis and inflammatory bowel diseases, in which both are associated with the IL23-R gene ${ }^{10}$. A highly significant relationship between Crohn's disease and the gene for IL23-R localized on chromosome $1 \mathrm{p} 31$ was confirmed by genomic association studies performed in patients with Crohn's disease ${ }^{11,12}$. 
Data on the improvement of IBD are available in patients suffering from psoriasis and who are undergoing anti-TNF therapy ${ }^{13}$. However, in patients suffering from IBD who are treated with anti-TNF drugs, paradoxical reactions, such as psoriasis are observed ${ }^{14}$. Another study pointed to the higher prevalence of microscopic inflammatory changes in the macroscopic normal intestinal mucosa in patients with psoriasis and psoriatic arthritis than in the general population ${ }^{15}$.

According to new findings, serological markers of IBD can be used as significant predictors to the development of the disease in asymptomatic patients ${ }^{16}$.

The aim of our project was to test the hypothesis that the prevalence of inflammatory gastrointestinal diseases, including coeliac disease, Crohn's disease and ulcerative colitis and the sensitive diagnostic markers of these conditions under study is higher in patients with the chronic stationary form of psoriasis than in the general population.

\section{MATERIALS AND METHODS}

The study was designed as a hospital-based case-control study. Patients with chronic plaque psoriasis were enrolled as cases. The control group, selected based on a ratio of $1: 2$, consists of patients with other skin diseases who complied with the same selection criteria applied in cases. A comparison of the prevalence of specific antibodies (ASCA, AEP, p-ANCA, AGC, EMA, ARA, t-TG, AGA) and non-specific signs of gastrointestinal diseases was carried out between cases and controls. The statistical significance of the differences between cases and controls was tested by means of the Chi-squared test or MannWhitney U test. We utilized binary logistic regression for the multivariate modelling of the associations between psoriasis and the aforementioned indicators.

\section{Study population}

Patients suffering from chronic plaque psoriasis were enrolled in this study. The controls were selected by means of frequency matching with a ratio of two controls to one case. These were selected from among other patients not suffering from psoriasis. The cases and controls were subject to the same selection criteria: all persons suffering from chronic and autoimmune diseases were excluded.

\section{Scope of medical examination}

In each study subject, the following parameters were determined:

- ASCA - Anti- Saccharomyces cerevisiae antibodies IgA ( Crohn's disease)

- AEP - Anti- acinar cytoplasmic granule pancreatic antibodies IgG (Crohn's disease)

- P-ANCA - perinuclear antibodies to neutrophil granulocyte cytoplasm component $\operatorname{IgA}$ (Ulcerative colitis)

- AGC-Anti - goblet cell antibodies IgA(markers for inflammatory bowel disease)
- EMA - Anti - endomysium antibodies IgA, IgG (coeliac disease)

- ARA - Anti - reticuline antibodies IgA (coeliac disease)

- t-TG - Anti - transglutaminase antibodies IgA, IgG (coeliac disease)

- AGA - Anti - gliadine antibodies IgA, IgG (coeliac disease)

- nonspecific signs of gastrointestinal diseases

- blood count (erythrocytes $\times 10^{12} / \mathrm{L}$, leucocytes $\mathrm{x}$ $10^{9} / \mathrm{L}$, thrombocytes $\left.\times 10^{9} / \mathrm{L}\right)$

- haemoglobin $(\mathrm{g} / \mathrm{L})$

- iron level $(\mu \mathrm{mol} / \mathrm{L})$

- total serum protein level(g/L)

- C-reactive protein level (CRP - mg/L)

\section{Statistical analysis}

Due to the asymmetric distribution of most variables studied, the differences between cases and controls were tested by means of the Mann-Whitney U test. In some cases, the data were logarithmically transformed to normalize the distribution. The statistical associations between categorical variables were tested using the Chi-squared test. The simultaneous effects of the studied variables on the occurrences of psoriasis were studied using binary logistic regression. The point estimates of odds ratios and 95\% CI describing the strength of association between independent predictors and occurrence of psoriasis are reported. The level of statistical significance in all tests was set to $\alpha=0.05$.

\section{RESULTS}

Data for 189 cases and 378 controls were available. The main characteristics and the distribution of studied parameters are listed in tables (Table 1-3).

There were statistically significant differences between cases and controls for several important parameters. There were significant differences $(P<0.05)$ in the following parameters: leucocyte count, CRP, total protein, transglutaminase IgA antibodies and p-ANCA (Table 1, 2).

In the binary logistical model, the following parameters were associated with psoriasis: leucocyte count (Table 3, Fig. 1) and p-ANCA (Table 3, Fig. 2) (for all parameters included in the logistical model $P \leq 0.001$ ).

\section{DISCUSSION}

The results showed statistically significant differences in tTG-IgA between patients with psoriasis and controls. Anti - transglutaminase antibodies (tTG) are pathognomonic, highly sensitive $90-98 \%$, and specific $95-97 \%$ to coeliac disease. The negativity of tTG practically excludes coeliac disease. The positivity of tTG must to be verified by biopsy of the small intestine mucosa. False positive results of tTG may occur in chronic hepatic and liver 
Biomed Pap Med Fac Univ Palacky Olomouc Czech Repub. 2016 Mar; 160(1):100-105.

Table 1. Distributions of studied parameters and their comparison in controls and cases.

\begin{tabular}{llllccccc}
\hline Variable & Status & $\mathrm{N}$ & Mean & Median & Minimum & Maximum & $\begin{array}{c}\text { Std. } \\
\text { Deviation }\end{array}$ & Sig. \\
\hline Leukocytes $(\mathrm{x} \mathrm{10} / \mathrm{L})$ & Control & 378 & 6.72 & 6.4 & 3.00 & 15.4 & 1.88 & 0.000 \\
& Case & 188 & 7.67 & 7.1 & 4.00 & 17.2 & 2.17 & \\
& Total & 566 & 7.3 & 6.6 & 3.00 & 17.2 & 2.3 & \\
CRP $(\mathrm{mg} / \mathrm{L})$ & Control & 377 & 2.8 & 1.4 & 0.1 & 34.0 & 4.12 & 0.004 \\
& Case & 186 & 3.71 & 1.95 & 0.2 & 71.1 & 6.50 & \\
Total protein $(\mathrm{g} / \mathrm{L})$ & Total & 563 & 3.1 & 1.5 & 0.1 & 71.1 & 5.4 & \\
& Control & 377 & 74.57 & 74.0 & 60 & 88 & 4.31 & 0.046 \\
& Case & 189 & 73.76 & 74.0 & 55 & 86 & 4.90 & \\
Iron level $(\mu \mathrm{mol} / \mathrm{L})$ & Total & 566 & 74.30 & 74.0 & 55 & 88 & 4.53 & \\
& Control & 377 & 17.83 & 17.50 & 3.1 & 44.8 & 6.91 & 0.686 \\
& Case & 189 & 18.3 & 16.80 & 2.6 & 40.1 & 6.46 & 6.76 \\
\hline
\end{tabular}

Table 2. Distributions of studied parameters and their comparison in controls and cases.

\begin{tabular}{|c|c|c|c|c|c|c|c|c|}
\hline & & \multicolumn{2}{|c|}{ Status } & \multirow{2}{*}{ Total } & \multirow{2}{*}{ OR } & \multicolumn{2}{|c|}{$95 \% \mathrm{CI}$ for OR } & \multirow{2}{*}{ Sig } \\
\hline & & Control & Case & & & Lower & Upper & \\
\hline \multirow[t]{2}{*}{ Gender } & Male & 194 & 111 & 305 & & & & \\
\hline & Female & 184 & 78 & 262 & 0.741 & 0.521 & 1.054 & 0.095 \\
\hline Total & & 378 & 189 & 567 & & & & \\
\hline \multirow[t]{2}{*}{ ARA } & Neg. & 377 & 186 & 563 & & & & \\
\hline & Pozit. & 1 & 3 & 4 & 6.081 & 0.628 & 58.855 & 0.076 \\
\hline Total & & 378 & 189 & 567 & & & & \\
\hline \multirow[t]{2}{*}{ Endo_IgA } & Neg. & 378 & 188 & 566 & & & & \\
\hline & Pozit. & 0 & 1 & 1 & - & & & 0.157 \\
\hline Total & & 378 & 189 & 567 & & & & \\
\hline \multirow[t]{2}{*}{ Endo_IgG } & Neg. & 378 & 188 & 566 & & & & \\
\hline & Pozit. & 0 & 1 & 1 & - & & & 0.157 \\
\hline Total & & 378 & 189 & 567 & & & & \\
\hline \multirow{2}{*}{ AGA_IgA } & Neg. & 355 & 171 & 526 & & & & \\
\hline & Pozit. & 23 & 18 & 41 & 1.625 & 0.854 & 3.091 & 0.136 \\
\hline Total & & 378 & 189 & 567 & & & & \\
\hline \multirow[t]{2}{*}{ AGA_IgG } & Neg. & 337 & 163 & 500 & & & & \\
\hline & Pozit. & 41 & 26 & 67 & 1.311 & 0.775 & 2.218 & 0.321 \\
\hline Total & & 378 & 189 & 567 & & & & \\
\hline \multirow[t]{2}{*}{ tTG_IgA } & Neg. & 378 & 187 & 565 & & & & \\
\hline & Pozit. & 0 & 2 & 2 & - & & & 0.045 \\
\hline Total & & 378 & 189 & 567 & & & & \\
\hline \multirow[t]{2}{*}{ tTG_IgG } & Neg. & 376 & 186 & 562 & & & & \\
\hline & Pozit. & 2 & 3 & 5 & 3.032 & 0.502 & 18.304 & 0.204 \\
\hline Total & & 378 & 189 & 567 & & & & \\
\hline \multirow[t]{2}{*}{ ASCA } & Neg. & 372 & 181 & 553 & & & & \\
\hline & Pozit. & 6 & 8 & 14 & 2.740 & 0.937 & 8.016 & 0.056 \\
\hline Total & & 378 & 189 & 567 & & & & \\
\hline \multirow[t]{2}{*}{ AEP } & Neg. & 376 & 188 & 564 & & & & \\
\hline & Pozit. & 2 & 1 & 3 & 1.000 & 0.090 & 11.099 & 1.000 \\
\hline Total & & 378 & 189 & 567 & & & & \\
\hline \multirow[t]{2}{*}{ pANCA } & Neg. & 367 & 171 & 538 & & & & \\
\hline & Pozit. & 11 & 18 & 29 & 3.512 & 1.623 & 7.598 & 0.001 \\
\hline Total & & 378 & 189 & 567 & & & & \\
\hline \multirow[t]{2}{*}{ AGC } & Neg. & 366 & 181 & 547 & & & & \\
\hline & Pozit. & 12 & 8 & 20 & 1.348 & 0.541 & 3.356 & 0.52 \\
\hline Total & & 378 & 189 & 567 & & & & \\
\hline
\end{tabular}


diseases, in monoclonal gammopathy and in other autoimmune diseases ${ }^{1}$.

Unlike the results of Nagui et al. ${ }^{17}$, our results showed no statistically significant difference in AGA between the cases and controls. Statistically significant differences in AGA between patients with psoriasis and controls were not confirmed by other studies either ${ }^{18,19}$.

Anti-gliadine antibodies (AGA) for both IgA and IgG have a wide range of values for sensitivity and specificity. The positive predictive value is very low. AGA can be positive in a number of diseases: gastrointestinal opportunist infections, milk protein allergy, IgA nephropathy, inflammatory bowel diseases etc. Anti-gliadine antibodies are also found in healthy individuals and lack any essential significance in diagnosing and screening for coeliac disease in clinical practice ${ }^{17}$.

Based on the positive anti-transglutaminase antibodies which are a highly sensitive and specific marker of coeliac disease, we can confirm the association between coeliac disease and psoriasis. In other words, this result shows a higher prevalence of coeliac disease in patients with psoriasis than in the general population ${ }^{1,2,4}$. For this reason, dermatologists and general practitioners are advised to ask their psoriatic patients questions concerning bowel problems, and to perform tests for coeliac disease via thorough examination ${ }^{2}$. The early diagnosis of coeliac disease by detecting specific antibodies can prevent complications that can occur in untreated disease.

In the case of a positive antibody test in psoriatic patients, a gluten-free diet may be considered ${ }^{3}$. An early diagnosis and adherence to a gluten-free diet for 3-6 months leads to an improvement of skin psoriatic lesions without any pharmacological treatment ${ }^{3,4}$ and thus significantly improves the quality of life of these patients. The effect of a gluten- free diet on psoriatic lesions has not been clearly explained. Some authors suggest that the activation of $\mathrm{T}$ cells and abnormal absorption of antigens due to inflammation of the gut play an important role in the pathogenesis of psoriatic lesions. This may be due to reactivity to the antigen present in the intestinal mucosa and in the skin, and is associated with gluten, but also nonspecifically to cytokines induced in the intestinal mucosa during the development of inflammatory diseases ${ }^{3,20}$.

The diagnostics of celiac disease is based on clinical manifestation, positive serological markers and subsequent biopsy of the intestinal mucosa with histological evidence of villous atrophy. In latent disease, serological markers are positive without enteropathy. In this case the enteropathy may occur later, and this should be taken into account in the future ${ }^{1,21}$

The elevation of CRP and leukocytes could indicate inflammatory bowel disease. This needs to be interpreted with caution since these are nonspecific markers of intestinal inflammation and could be elevated due to another type of inflammation ${ }^{22}$.

The serum antibodies p-ANCA used in the screening of ulcerative colitis have a high specificity (85-97\%) but a low sensitivity (50-70\%), when used alone. The presence of p-ANCA and ASCA antibodies found simultaneously may help to differentiate between Crohn's disease and

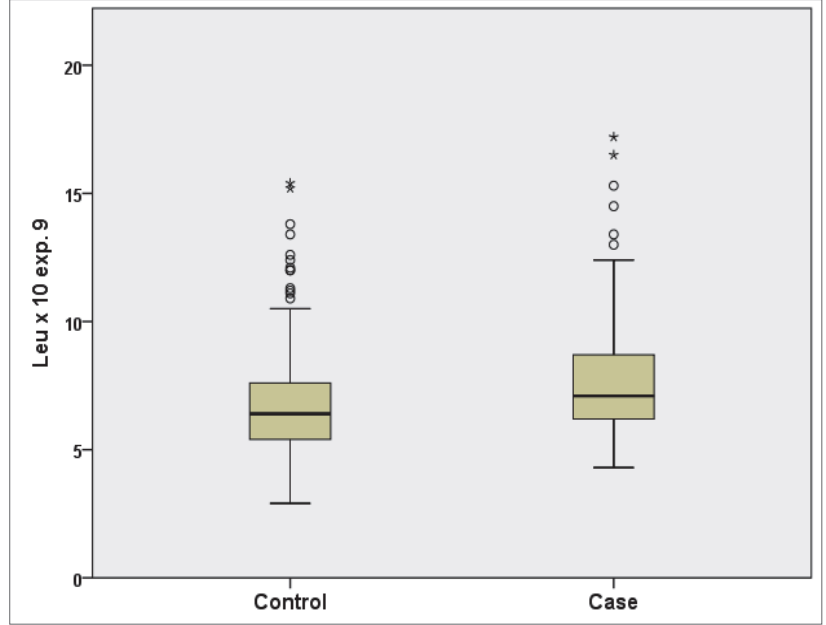

Fig. 1. Leucocytes count in psoriatic patients and controls.

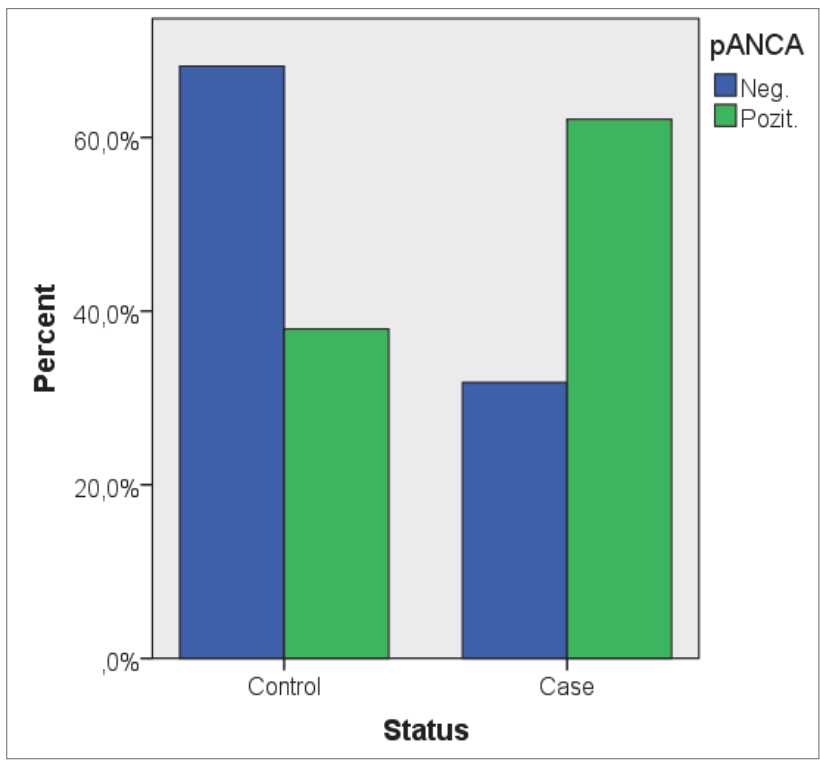

Fig. 2. P-ANCA in psoriatic patients and controls.

Table 3. Binary logistic regress in model of the association between psoriasis occurrence and studied parameters.

\begin{tabular}{lcccc}
\hline \multirow{2}{*}{ Variable } & OR & \multicolumn{2}{c}{$95 \%$ C.I.for OR } & \multirow{2}{*}{ Sig. } \\
\cline { 3 - 4 } & & Lower & Upper & \\
\hline Leukocytes $\left(\times 10^{9} / \mathrm{L}\right)$ & 1.222 & 1.109 & 1.346 & 0.000 \\
LDL (mmol/L) & 1.313 & 1.061 & 1.625 & 0.012 \\
pANCA & 3.323 & 1.446 & 7.636 & 0.005 \\
\hline
\end{tabular}

ulcerative colitis. The positivity of p-ANCA and negativity of ASCA antibodies has a sensitivity of $43 \%$ and a specificity of $100 \%$ in ulcerative colitis. In Crohn's disease, ASCA positivity and p-ANCA negativity has a sensitivity of $57 \%$ and specificity of $93 \%$ (ref. ${ }^{23}$ ). Possible false positives must be considered, as p-ANCA may occur in 
patients with other autoimmune diseases, such as microscopic polyangiitis, rapidly progressive glomerulonephropathy, Churg-Strauss syndrome, rheumatoid arthritis and lupus erythematosus.

Generally, in autoimmune diseases, serum antibodies may precede the manifested form of the disease by several years ${ }^{16}$. In a study conducted in the Israeli army, the investigations of ASCA and p-ANCA in healthy individuals were regularly performed. Crohn's disease developed in 32 cases and ulcerative colitis in 8 cases. The data from this screening confirm that the antibodies may precede the manifestation of inflammatory bowel diseases. In 10 out of 32 patients with Crohn's disease (31\%), the positivity of ASCA preceded the clinical manifestation by approximately 38 months. In the control group, 95 individuals were enrolled and ASCA antibodies were negative in all of them $(0 \%)$. In the case of ulcerative colitis, the positivity of p-ANCA had been detected in 2 of 8 soldiers before the diagnosis, i.e. $25 \%$ of the subjects. The control group consisted of 24 subjects and p-ANCA antibodies were negative in all controls ${ }^{24}$.

Based on these results, van Schaik et al. performed a similar study on a larger group of patients. They found the following results: in 77 patients with Crohn's disease, the detection of ASCA preceded the disease manifestation in 30 individuals (39\%) and in 167 cases with ulcerative colitis, the positivity of p-ANCA preceded the disease manifestation in 58 individuals (35\%) (ref. $\left.{ }^{16}\right)$. The mean interval between the detection of antibodies and the diagnosis of the disease was longer in this study in comparison to the Israeli's study. In the case of Crohn's disease and ulcerative colitis, the interval was approximately 4.5 years ${ }^{16}$. The average delay in diagnosing IBD was estimated at 9 months in Crohn's disease and 4 months in ulcerative colitis ${ }^{16}$.

The positivity of antibodies without clinical symptoms could be a marker of latent disease and a clinical manifestation may occur later. In the case of positive antibodies and clinically suspected IBD, the patient should be referred to gastroenterology, where an intestinal mucosa biopsy and histological verification of the diagnosis can be carried out ${ }^{9}$.

\section{CONCLUSION}

The results of this study show significant differences in selected parameters between cases and controls. For this reason, regular screening of t-TG IgA and p-ANCA antibodies in patients with the chronic stationary form of psoriasis should become standard procedure for dermatologists working in cooperation with general practitioners.

Early diagnosis of gastrointestinal diseases and risk factors will greatly improve patient's quality of life, and the early treatment of comorbidities will reduce the cost of treating the complications of these diseases. Psoriatic patients should also be made aware of possible associated diseases, and a healthy lifestyle for preventing the development of comorbidities.
The care of patients suffering from psoriasis should focus on primary and secondary prevention.

Acknowledgement: The project was supported by the Internal Grant Agency of the Ministry of Health of the Czech Republic (Grant NT 13275/4).

Author contributions: KJ: manuscript writing, data collection; JV: manuscript editing, data collection; MD: data collection; DG, JH: results interpretation; ZS: data analysis.

Conflict of interest statement: None declared.

\section{REFERENCES}

1. Akbulut S, Gür G, Topal F, Senel E, Topal FE, Alli N, Saritas U. Coeliac disease-associated antibodies in psoriasis. Ann Dermatol 2013;25(3):298-303.

2. Birkenfeld S, Dreiher J, Weitzman D, Cohen AD. Coeliac disease associated with psoriasis. Br J Dermatol 2009;161:1331-4.

3. Bhatia BK, Millsop JW, Debbaneh M, Koo J, Linos E, Liao W. Diet and psoriasis, part II: celiac disease and role of a gluten-free diet. J Am Acad Dermatol 2014;71(2):350-8.

4. De Bastiani R, Gabrielli M, Lora L, Napoli L, Tosetti C, Pirrotta E, Ubaldi E, Bertolusso L, Zamparella M, De Polo M, Nebiacolombo C, Bortot M, Mancuso M,Bacchin P, Marsala V, Pinna R, Tursi A, Benedetto E, Cuffari A, Pati A, Di Caro S, Perenzin G, Sala R, Calzavara Pinton G, Gasbarrini A. Association between Coeliac Disease and Psoriasis: Italian Primary Care Multicentre Study. Dermatology 2015;230(2):156-60.

5. Saurabh Aggarwal, Benjamin Lebwohl, Peter H. R. Green. Screening for celiac disease in average-risk and high-risk populations. Therap Adv Gastroenterol 201;5(1):37-47.

6. Porcelli B, Ferretti F, Vindigni C, Terzuoli L. Assessment of a Test for the Screening and Diagnosis of Celiac Disease. J Clin Lab Anal 2014. doi: 10.1002/jcla.21816

7. Brusca I. Overview of biomarkers for diagnosis and monitoring of celiac disease. Adv Clin Chem 2015;68:1-55. doi: 10.1016/ bs.acc.2014.12.006

8. Aust $\mathrm{DE}$, Bläker $\mathrm{H}$. Histological diagnosis and complications of celiac disease : Update according to the new S2k guidelines. Pathologe 2015;36(2):197-207. doi: 10.1007/s00292-015-0006-2 German.

9. Shor DB, Orbach H, Boaz M, Altman A, Anaya JM, Bizzaro N, Tincani A, Cervera R, Espinosa G, Stojanovich L, Rozman B, Bombardieri S, Vita SD,Damoiseaux J, Villalta D, Tonutti E, Tozzoli R, Barzilai O, Ram M, Blank M, Agmon-Levin N, Shoenfeld Y. Gastrointestinal-associated autoantibodies in different autoimmune diseases. Am J Clin Exp Immunol 2012;1(1):49-55.

10. Einarsdottir E, Koskinen LL, Dukes E, Kainu K, Suomela S, Lappalainen M, Ziberna F, Korponay-Szabo IR, Kurppa K, Kaukinen K, Adány R, Pocsai Z, Széles G, Färkkilä M, Turunen U, Halme L, PaavolaSakki P, Not T, Vatta S, Ventura A, Löfberg R, Torkvist L, Bresso F, Halfvarson J, Mäki M, Kontula K, Saarialho-Kere U, Kere J, D'Amato M, Saavalainen P. IL23R in the Swedish, Finnish, Hungarian and Italian populations: association with IBD and psoriasis, and linkage to celiac disease. BMC Med Genet 2009 28;10:8.

11. Zhang XJ, Huang W, Yang $S$ et al. Psoriasis genome-wide association study identifies susceptibility variants within LCE gene cluster at 1q21. Nat Genet 2009;41:205-10.

12. Van Limbergen J, Wilson DC, Satsangi J. The genetics of Crohn's disease. Annu Rev Genomics Hum Genet 2009;10:89-116.

13. Cosmi L, Liotta F, Maggi E, Romagnani S, Annunziato F. Th17 and non-classic Th1 cells in chronic inflammatory disorders: two sides of the same coin. Int Arch Allergy Immunol 2014;164(3):171-7. Review doi: 10.1159/000363502

14. Cullen G, Kroshinsky D, Cheifetz AS, Korzenik JR. Psoriasis associated with anti-tumour necrosis factor therapy in inflammatory bowel disease: a new series and a review of 120 cases from the literature. Aliment Pharmacol Ther 2011;34(11-12):1318-27. 
15. Li WQ, Han JL, Chan AT, Qureshi AA. Psoriasis, psoriatic arthritis and increased risk of incident Crohn's disease in US women. Ann Rheum Dis 2013;72(7):1200-5.

16. van Schaik FD, Oldenburg $B$, Hart AR, Siersema PD, Lindgren $S$ Grip O, Teucher B, Kaaks R, Bergmann MM, Boeing H, Carbonnel F, Jantchou P, Boutron-Ruault MC, Tjønneland A, Olsen A, Crowe FL, Peeters PH, van Oijen MG, Bueno-de-Mesquita HB. Serological markers predict inflammatory bowel disease years before the diagnosis. Gut 2013;62(5):683-8.

17. Nagui N, El Nabarawy E, Mahgoub D, Mashaly HM, Saad NE, El-Deeb DF. Estimation of (IgA) anti-gliadin, anti-endomysium and tissue transglutaminase in the serum of patients with psoriasis. Clin Exp Dermatol 2011;36(3):302-4.

18. Sultan SJ, Ahmad QM, Sultan ST. Antigliadin antibodies in psoriasis. Australas J Dermatol 2010;51(4):238-42.

19. Khan JM, Rao SU, Rathore MU, Janjua W. Association between psoriasis and coeliac disease related antibodies. J Ayub Med Col Abbottabad 2014;26(2):203-6.
20. Michaëlsson G, Gerdén B, Hagforsen E, Nilsson B, Pihl- Lundin I, Kraaz W, et al. Psoriasis patients with antibodies to gliadin can be improved by a gluten-free diet. Br J Dermatol 2000;142:44-51.

21. Damasiewicz-Bodzek A, Wielkoszyński T. Serologic markers of celiac disease in psoriatic patients. J Eur Acad Dermatol Venereol 2008;22(9):1055-61.

22. Cekic C, Arabul M, Alper E, Pakoz ZB, Saritas E, Yuksel, Ünsal B. . Evaluation of the relationship between serum ghrelin, C-reactive protein and interleukin- 6 levels, and disease activity in inflammatory bowel diseases. Hepatogastroenterology 2014;61(133):1196-200.

23. Nisihara RM, de Carvalho WB, Utiyama SR, Amarante $H$, Baptista ML. Diagnostic role and clinical association of ASCA and ANCA in Brazilian patients with inflammatory bowel disease. Dig Dis Sci 2010;55(8):2309-15. doi: 10.1007/s10620-009-0998-7

24. Israeli E, Grotto I, Gilburd B, Balicer RD, Goldin E, Wiik A, Shoenfeld Y. Anti-Saccharomyces cerevisiae and antineutrophil cytoplasmic antibodies as predictors of inflammatory bowel disease. Gut 2005;54(9):1232-6. 